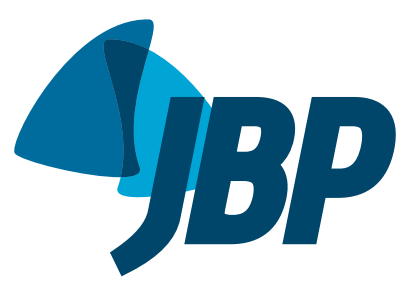
Medicine Department, Centro Hospitalar do Porto, Hospital de Santo António, Porto, Portugal.

2. Cardiology Service, Medicine Department, Centro Hospitalar do Porto, Hospital de Santo António, Porto Portugal.

3. Department of Physiology and Cardiothoracic Surgery, Faculty of Medicine of Porto, Porto, Portugal.

4. Internal Medicine Service, Medicine Department, Centro Hospitalar do Porto, Hospital de Santo António, Porto Portugal.

5. Center for Research and Development in Mathematics and Applications, Department of Mathematics, University of Aveiro, Aveiro, Portugal.

6. School of Health, University of Aveiro, Aveiro, Portugal.

7. Institute of Electronics and Telematics Engineering of Aveiro, University of Aveiro, Aveiro, Portugal.

8. MedlnUP, Department of Pharmacology and Therapeutics, Faculty of Medicine, University of Porto, Porto, Portugal

9. Department of Medical Sciences, University of Aveiro, Aveiro, Portugal.

a. iD http://orcid.org/0000-0003-4976-3781

b. (iD) http://orcid.org/0000-0002-4509-0260

c. (iD http://orcid.org/0000-0003-3985-0718

d. (iD) http://orcid.org/0000-0001-5228-2984

e. (iD http://orcid.org/0000-0002-5673-8683

f. (iD) http://orcid.org/0000-0002-3172-7400

g. iD $h t t p: / / o r c i d . o r g / 0000-0002-4861-8649$

h. (iD http://orcid.org/0000-0003-3801-7249

Submitted: 01 November 2017 Accepted: 12 August 2018

Study carried out at Centro Hospitalar do Porto, Hospital de Santo António, Porto, Portugal.

\section{Disability and its clinical correlates in pulmonary hypertension measured through the World Health Organization Disability Assessment Schedule 2.0: a prospective, observational study}

\author{
Abílio Reis ${ }^{1, a}$, Mário Santos ${ }^{1,2,3, b}$, Inês Furtado ${ }^{4, c}$, Célia Cruz $^{4, d}$, \\ Pedro Sa-Couto ${ }^{5, e}$, Alexandra Queirós ${ }^{6,7, f}$, Luís Almeida ${ }^{8, g}$, Nelson Rocha7,9,h
}

\begin{abstract}
Objective: To characterise the degree of disability in pulmonary hypertension (PH) patients based on the World Health Organisation Disability Assessment Schedule 2.0 (WHODAS 2.0). Method: A prospective and observational study of patients with documented $\mathrm{PH}(\mathrm{N}=46)$. Patients completed the WHODAS 2.0 questionnaire during a scheduled routine clinical visit, and their demographic and clinical characteristics were retrieved from electronic medical records (EMR). In subsequent visits, selected clinical variables were registered to assess disease progression. Results: WHODAS 2.0 scores were indicative of mild to moderate disability for the domains of mobility $(22.0 \pm 23.2)$, life activities $(23.7 \pm 25.5)$, and participation in society $(17.2 \pm 15.9)$, as well as total WHODAS 2.0 score $(15.3 \pm 15.2)$. For the domains of cognition $(9.1 \pm 14.1)$, self-care $(8.3 \pm 14.4)$, and interpersonal relationships (11.7 \pm 15.7$)$, scores were lower. Disability scores were, generally, proportional to the $\mathrm{PH}$ severity. The main baseline correlates of disability were World Health Organisation (WHO) functional class, fatigue, dyspnoea, 6-minute walking distance (6MWD), and N-terminal pro b-type natriuretic peptide (NTproBNP). Baseline WHODAS 2.0 scores showed significant associations with disease progression. However, this effect was not transversal to all domains, with only a few domains significantly associated with disease progression variables. Conclusions: This $\mathrm{PH}$ population shows mild disability, with higher degree of disability in the domains of mobility and life activities. This study is the first one to assess disability in $\mathrm{PH}$ using WHODAS 2.0. Further studies should apply this scale to larger $\mathrm{PH}$ populations with suitable representations of more severe $\mathrm{PH}$ forms.
\end{abstract}

Keywords: Pulmonary hypertension; International Classification of Functioning, Disability and Health; Disability evaluation; Quality of Life.

\section{INTRODUCTION}

Pulmonary hypertension ( $\mathrm{PH}$ ) encompasses a set of heterogeneous progressive conditions characterised by increased pulmonary artery pressure, which, if left untreated, leads to right ventricular failure, causing substantial morbidity and, ultimately, premature death. ${ }^{(1)}$ Fortunately, several $\mathrm{PH}$-specific treatments were introduced over the past decades, resulting in considerable gains in terms of long-term patient survival. ${ }^{(2,3)}$ Since then, research shifted towards more intense evaluation of functional capacity and quality of life to ensure effective, patientcentered management of this highly debilitating condition. ${ }^{(4,5)}$ Disability due to $\mathrm{PH}$ is multifactorial, depending on factors such as decreased exercise capacity, functional limitation, compensatory physiological mechanisms, psychological impact of the disease, as well as drug adverse effects, and burden of treatment. ${ }^{(6)}$

Several types of instruments have been used in patients with $\mathrm{PH}$ to evaluate functionality, health-related quality of life and quality of life, ${ }^{(4,5)}$ including general assessment questionnaires, ${ }^{(7-9)}$ as well as disease-specific questionnaires. ${ }^{(10-15)}$ Health-related quality of life (HRQOL) has also been evaluated as a prognostic factor and treatment goal in the clinical management of $\mathrm{PH} .{ }^{(16)}$ However, to our knowledge, no specific evaluation of functioning and disability in $\mathrm{PH}$ populations

Correspondence to:

Abílio Reis. Pulmonary Vascular Disease Unit, Centro Hospitalar do Porto, Hospital de Santo António, Largo Professor Abel Salazar, CEP 4099-001, Porto,

Portugal.

Tel.: +351917645915. E-mail: reisabilio@gmail.com

Financial support: Portuguese Foundation for Science and Technology (Fundação para a Ciência e a Tecnologia—FCT) and Actelion Pharmaceuticals Portugal. 
has been done using the standardised functioning and disability classification developed by the World Health Organisation (WHO), the International Classification of Functioning, Disability and Health (ICF). ${ }^{(17)}$

The ICF does not classify people, but rather interprets their characteristics, namely, body structures and functions, activities and participation, and the influences of the environment, which allows to properly describe functional states. Functioning or disability are considered as a result of a dynamic interaction between health conditions and contextual factors. ${ }^{(17)}$ Using this framework is important, because, although functioning and disability are intercorrelated with HRQOL, this framework provides an objective measure of functioning (i.e., objective ability to perform in a given life domain), while HRQOL assessments provide a subjective measure of well-being (i.e., subjective feeling about the ability to perform in a given life domain). ${ }^{(18)}$ ICF is operationalized through the WHO Disability Assessment Schedule 2.0 (WHODAS 2.0), which is a generic instrument for assessing health status and disability across different cultures and settings. ${ }^{18,19)}$ WHODAS 2.0 has increasingly been used in clinical practice and described in the medical literature, and it is considered the leading standard measure of disability worldwide. ${ }^{(19)}$ Although being a generic, standardised measure, its psychometric proprieties have been repeatedly validated in diverse populations, locations, and languages, which makes WHODAS 2.0 the tool of choice in comparing disability due to different disease conditions and makes it possible to monitor the impact of health-related interventions. ${ }^{(18,19)}$

This study aimed to characterise the degree of disability in a population of Portuguese $\mathrm{PH}$ patients based on the WHODAS 2.0, and to identify clinical correlates of disability. Additionally, the study purposed to explore the capacity of WHODAS 2.0 in predicting the clinical evolution of $\mathrm{PH}$ patients.

\section{METHODS}

\section{Study design and population}

This is a prospective, observational study of prevalent $\mathrm{PH}$ patients (confirmed through right heart catheterisation) followed at a single reference centre in the North of Portugal (Pulmonary Vascular Disease Unit of Hospital de Santo António, Centro Hospitalar do Porto, Porto, Portugal); the centre is part of the European Reference Network for Rare or Low Prevalence Complex Diseases (ERN-LUNG), and covers a region with approximately 3.8 million adult population.

When attending a routine clinical visit, patients were consecutively invited to participate in the study. Patients were eligible to participate if they were $\geq 18$ years old and able and willing to give their informed consent. Patients were excluded from the study if they were unable to complete the study data collection forms due to illiteracy or cognitive impairment, or if they were not able to comply with the study protocol, due to other medical conditions or personal circumstances. Patients with group 2 and $3 \mathrm{PH}$ were excluded from the study.

All patients provided their written informed consent prior to enrolment. The study protocol and data collection instruments received favourable opinion by the Ethics Committee of Centro Hospitalar do Porto (Porto, Portugal) and were reviewed and approved by the Portuguese National Data Protection Commission.

\section{Data collection}

Data were collected by self-administering the Portuguese validated version of WHODAS 2.0 questionnaire during a scheduled routine clinical visit. Sociodemographic and disease-specific clinical measures, including haemodynamic ones, were retrieved from the clinical database collected by the dedicated PH software created at the Unit, PAHTool (Inovultus, Santa Maria da Feira, Portugal).

\section{WHODAS 2.0}

WHODAS 2.0 can be self-administered and captures the level of functioning in six domains of life: cognition, mobility, self-care, getting along, life activities (household and work) and participation. The 36-item Portuguese validated version of WHODAS 2.0 was used in this study. ${ }^{(20)}$ WHODAS 2.0 scoring and interpretation were performed according to the WHODAS 2.0 manual. ${ }^{(18)}$ The complex scoring method was used. This scoring consists of three essential steps:

- summing of recoded item scores within each domain

- summing of all six domain scores;

- converting the summary score into a metric ranging from 0 to 100 , in which 0 is no disability and 100 means full disability.

\section{Statistical analysis}

Descriptive data are presented as mean \pm standard deviation (SD) or frequency (\%). Differences in mean WHODAS scores for different subgroups were tested using one-way ANOVA/Kruskal-Wallis test. For the purposes of analysis, patients with group 1 and group $5 \mathrm{PH}$ were grouped, since there were only three patients in group 5 and all patients received $\mathrm{PH}$-specific treatment.

Bivariate correlation analysis correlating patients' demographic and clinical variables with WHODAS scores was conducted by using Spearman's Rank correlation coefficient (between quantitative variables) and by using point-biserial correlation (between quantitative variables and binary nominal variables). Then, multiple linear regression analysis was established only for the significant correlations to identify possible predictors for WHODAS scores. The method of selecting significant variables was the forward likelihood ratio (stepping method criteria: entry $=0.05$; removal $=0.10$ ), and no estimation problems were found. A dummy 
variable technique was used to incorporate qualitative independent variables in the regression models.

For the variables measured at the end of the study: disease progression, functional class, 6-minute walking distance (6MWD), N-terminal pro b-type natriuretic peptide (NT-proBNP), and risk classification, prediction models based on WHODAS dimensions or WHODAS total score were established. For the first two variables, binary regression models were used. For the following two variables, linear multiple regression models were derived. For the last variable, an ordinal regression model was conducted (using the probit link function).

Statistical analyses were conducted with Statistical Package for the Social Sciences (SPSS) Statistics for Windows, version 23.0 (IBM Corp, Armonk, NY, United States), and results were considered significant if $p$ $<0.05$.

\section{RESULTS}

\section{Patient characteristics}

Patient characteristics at baseline are summarised in Table 1. This was a prevalent, stable $\mathrm{PH}$ population, diagnosed through right heart catheterisation with a mean disease duration of approximately 6.8 years. Most participants were female $(63.0 \%)$, and the mean age of the study population was $54.5 \pm 16.2$ years. The most frequent $\mathrm{PH}$ aetiologies were chronic thromboembolic pulmonary hypertension (CTEPH) (30.4\%), idiopathic/ heritable pulmonary arterial hypertension (I/HPAH) (17.4\%), connective tissue diseases (CTD) (17.4\%), and congenital heart diseases (CHD) (15.2\%). For the purpose of analysis, aetiologies are from here on grouped as group 1 and $5 \mathrm{PH}(69.6 \%)$ and group 4 $\mathrm{PH}(30.4 \%)$. Comorbidities were frequent, present in $67.4 \%$ of patients, with a mean of approximately two comorbidities per patient ( range $=6 ; \mathrm{Q} 1=0 ; \mathrm{Q} 3=3$ ).

Overall, this population showed $\mathrm{PH}$ disease markers indicative of low (26.0\%), intermediate (54.3\%) and high (19.5\%) estimated 1-year mortality risk, according to the 2015 European Society of Cardiology (ESC)/European Respiratory Society (ERS) guidelines risk assessment scale. ${ }^{(1)}$ Most patients were in WHO functional classes I or II $(71.7 \%)$, with a mean 6MWD of $415.1 \pm 130.1$ meters. Self-reported dyspnoea was referred by $54.3 \%$ of patients and self-reported fatigue by $39.1 \%$. There was oxygen desaturation (94.0 \pm 3.1 to $82.3 \pm 9.2$ ) during 6MWT and a 2 -fold elevation NT-proBNP levels. PH-specific treatment was used in the vast majority of patients $(84.8 \%)$, $50 \%$ of them in combination therapy, all through oral route ( $100 \%$ of treated patients); only $12.8 \%$ were under $\mathrm{PH}$-specific treatment through parenteral route. Adjunctive treatment with oxygen (37.0\%), diuretics (50.0\%), and oral anticoagulants (60.9\%) was frequent.

\section{WHODAS 2.0 Disability scores}

WHODAS 2.0 scores were indicative of mild to moderate disability for the domains of mobility $(22.0$ $\pm 23.2)$, life activities (23.7 \pm 25.5$)$, and participation in society $(17.2 \pm 15.9)$. For the domains of cognition $(9.1 \pm 14.1)$, self-care $(8.3 \pm 14.4)$, and interpersonal relationships $(11.7 \pm 15.7)$, scores were lower. Mean WHODAS 2.0 total score was $15.3 \pm 15.2$, reflecting the variability between the different domains and indicating only mild general disability in the studied population.

Figure 1 presents mean WHODAS 2.0 scores measured in the study population at baseline according to gender and $\mathrm{PH}$ risk group. Mean WHODAS 2.0 scores were generally proportional to the $\mathrm{PH}$ risk classification, with higher risk patients showing higher degrees of disability. Mean WHODAS 2.0 total score was $8.7 \pm 9.0$ for low-risk patients, $15.4 \pm 14.9$ for intermediate-risk patients, and $24.1 \pm 19.2$ for highrisk patient $(p=0.150)$. As for the different domains, higher risk patients generally showed numerically higher WHODAS 2.0 scores, but the differences only reached statistical significance for the interpersonal relationship domain $(p=0.021)$. Women did not show significantly different scores from men for any domain.

\section{Clinical correlates of disability}

In bivariate analysis (Table 2), WHO Functional class and Borg fatigue index were the variables that showed stronger correlations with all domains, as well as the total WHODAS 2.0 score (correlation generally $>0.5$ or $<-0.5)$. For the life activities domain, fatigue was also strongly correlated (0.512), whereas for the participation in society domain the Borg dyspnea index was also strongly correlated (0.571). The total WHODAS 2.0 score was, in addition, strongly correlated with years of schooling $(-0.501)$, fatigue $(0.515)$, and the Borg dyspnea index (0.561). Figures S1 e S2 (Appendix) show scatterplots for correlations between WHODAS 2.0 scores and 6MWD. The Appendix is available online at http://jornaldepneumologia.com. br/detalhe_anexo.asp?id=62

Multivariate analysis (Table 3 ) showed substantially different results for each WHODAS 2.0 domain. For the cognition domain, the significant variables were WHO functional class and pulse pressure (systolic minus diastolic blood pressure). For the mobility domain, the significant variables were WHO functional class and self-reported fatigue. For the self-care domain, only WHO functional class was a statistically significant variable. For the interpersonal relationship domain, the Borg fatigue index and NT-proBNP were the significant variables. For the life activities domain, self-reported fatigue was the significant variable. For the domain of participation in society, the years of schooling, the Borg fatigue index, and pulse pressure were significant variables. Overall, for the total WHODAS 2.0 score, only self-reported fatigue and WHO functional class were significant factors in multivariate analysis.

\section{Disease progression}

Table 4 presents the evolution of the main $\mathrm{PH}$ disease markers at the final study visit. Over a mean 
Table 1. Sociodemographic and clinical characteristics of the study population at baseline.

\begin{tabular}{|c|c|}
\hline Characteristics & $\begin{array}{l}\text { PH patients } \\
(N=46)\end{array}$ \\
\hline Female, n (\%) & $29(63.0)$ \\
\hline Age, years & $54.5 \pm 16.2$ \\
\hline \multicolumn{2}{|l|}{ Marital status, n (\%) } \\
\hline Single/divorced/widowed & $14(30.4)$ \\
\hline Married/cohabitation & $32(69.6)$ \\
\hline \multicolumn{2}{|l|}{ Working status, $\mathrm{n}(\%)$} \\
\hline Full-time & $10(21.7)$ \\
\hline Retired/homemaker & $25(54.3)$ \\
\hline Unemployed & $11(23.9)$ \\
\hline \multicolumn{2}{|l|}{ Schooling, n (\%) } \\
\hline No formal education & $6(13.0)$ \\
\hline Basic education (up to 9 years) & $30(65.2)$ \\
\hline Secondary education (12 years) & $6(13.0)$ \\
\hline University education & $4(8.7)$ \\
\hline Disease duration, days & $2,487.2 \pm 3,199.9$ \\
\hline \multicolumn{2}{|l|}{ PH aetiology, n (\%) } \\
\hline $\mathrm{PAH}$ & $29(63.0)$ \\
\hline I/HPAH & $8(17.4)$ \\
\hline CTD & $8(17.4)$ \\
\hline CHD & $7(15.2)$ \\
\hline $\mathrm{PoPH}$ & $4(8.7)$ \\
\hline HIV & $2(4.3)$ \\
\hline Other & $3(6.5)$ \\
\hline Splenectomy & $2(4.3)$ \\
\hline Sarcoidosis & $1(2.2)$ \\
\hline CTEPH & $14(30.4)$ \\
\hline Comorbidities, n (\%) & $31(67.4)$ \\
\hline Comorbidities number per patient & $1.9 \pm 1.8$ \\
\hline Self-reported dyspnoea, n (\%) & $25(54.3)$ \\
\hline Self-reported fatigue, $\mathrm{n}(\%)$ & $18(39.1)$ \\
\hline \multicolumn{2}{|l|}{ WHO Functional class, $\mathrm{n}(\%)$} \\
\hline I/II & $33(71.7)$ \\
\hline III/IV & $13(28.3)$ \\
\hline NT-proBNP, pg/mL & $401.1 \pm 477.9$ \\
\hline 6MWD, meters & $415.1 \pm 130.1$ \\
\hline Borg (dyspnoea) & $1.7 \pm 2.6$ \\
\hline Borg (fatigue) & $2.8 \pm 2.8$ \\
\hline O, Sat_bas, \% & $94.0 \pm 3.1$ \\
\hline $\mathrm{O}_{2}$ Sat_mn, \% & $82.3 \pm 9.2$ \\
\hline Délta $\mathrm{O}_{2}$ Sat & $11.9 \pm 7.8$ \\
\hline SBP, mmHg & $117.2 \pm 20.2$ \\
\hline $\mathrm{DBP}, \mathrm{mmHg}$ & $67.1 \pm 13.2$ \\
\hline Pulse pressure, mmHg & $50.1 \pm 13.9$ \\
\hline Creatinine, $\mathrm{mg} / \mathrm{dL}$ & $0.9 \pm 0.3$ \\
\hline $\mathrm{RAP}, \mathrm{mmHg}$ & $7.9 \pm 4.4$ \\
\hline mPAP, mmHg & $46.0 \pm 15.9$ \\
\hline $\mathrm{Cl}, \mathrm{L} / \mathrm{min} / \mathrm{m}^{2}$ & $3.3 \pm 1.1$ \\
\hline PVR, Wood units & $6.0 \pm 3.4$ \\
\hline \multicolumn{2}{|l|}{$\mathrm{PH}$ risk classification, $\mathrm{n}(\%)$} \\
\hline Low & $12(26.0)$ \\
\hline Intermediate & $25(54.3)$ \\
\hline High & $9(19.5)$ \\
\hline Oxygen therapy, n (\%) & $17(37.0)$ \\
\hline Oral anticoagulants, n (\%) & $28(60.9)$ \\
\hline Diuretics, n (\%) & $23(50.0)$ \\
\hline PH-specific therapy, n (\%) & $39(84.8)$ \\
\hline Number of PH-specific drugs & $1.5 \pm 0.9$ \\
\hline Oral route, $\mathrm{n}(\%)$ & $39(84.8)$ \\
\hline Parenteral route, $\mathrm{n}(\%)$ & $5(10.9)$ \\
\hline Other drugs, number & $2.2 \pm 2.2$ \\
\hline \multicolumn{2}{|c|}{$\begin{array}{l}\text { Data displayed as mean } \pm \text { standard deviation (SD), except when otherwise indicated. PH: pulmonary hypertension; } \\
\text { PAH: pulmonary arterial hypertension; I/HPAH: idiopathic/heritable pulmonary arterial hypertension; CTD: } \\
\text { connective tissue diseases; CHD: congenital heart diseases; PoPH: portopulmonary hypertension; HIV: human } \\
\text { immunodeficiency virus; CTEPH: chronic thromboembolic pulmonary hypertension; WHO: World Health } \\
\text { Organization; NT-proBNP: N-terminal Pro b-type natriuretic peptide; 6MWD: 6-minute walking distance; SBP: } \\
\text { systolic blood pressure; DBP: diastolic blood pressure; RAP: right atrial pressure; mPAP: mean pulmonary arterial } \\
\text { pressure; CI: cardiac index; PVR: pulmonary vascular resistance; O2Sat_mn: minimum oxygen saturation; Sat_- } \\
\text { bas: baseline oxygen saturation. }\end{array}$} \\
\hline
\end{tabular}


西

(A) Disability according to gender

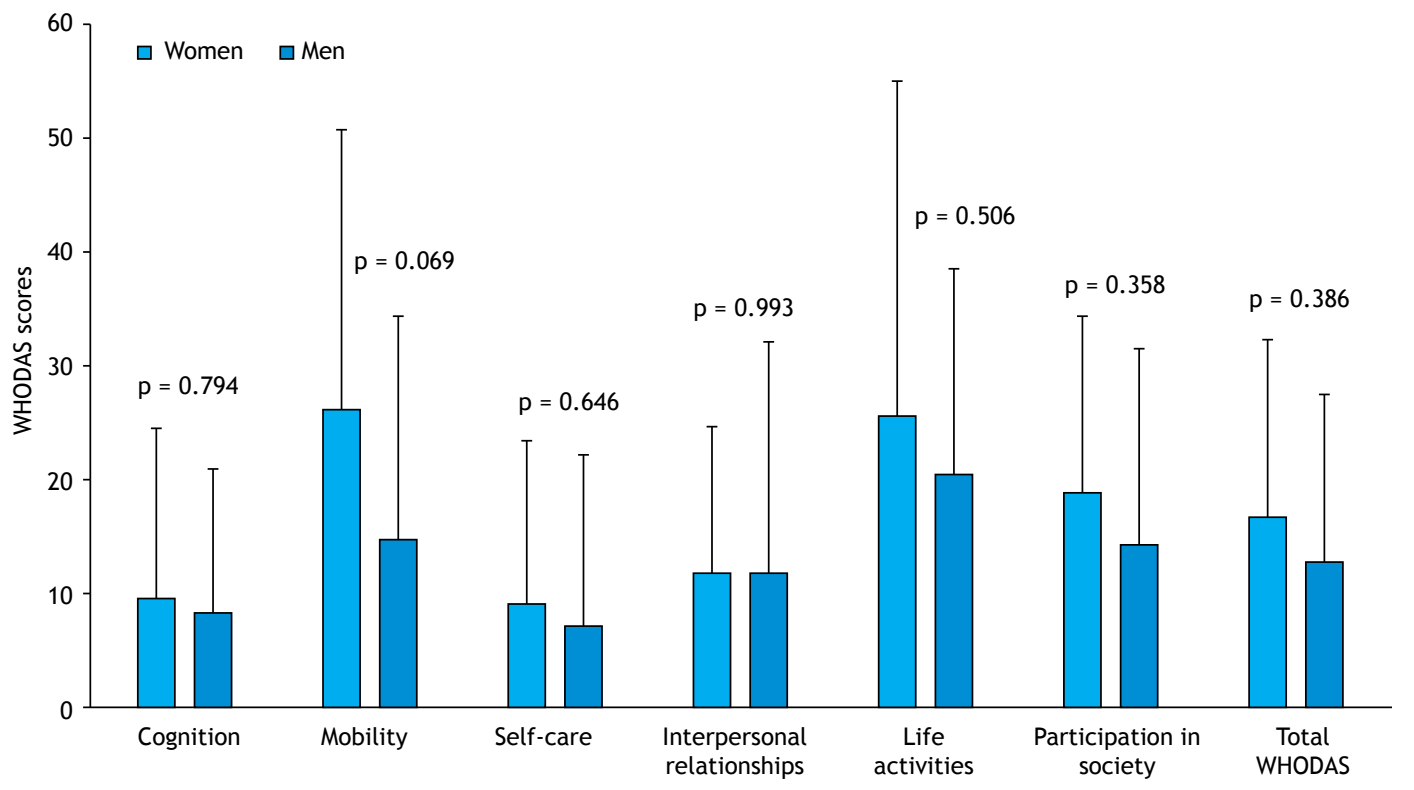

(B) Disability according to ESC/ERS risk classification

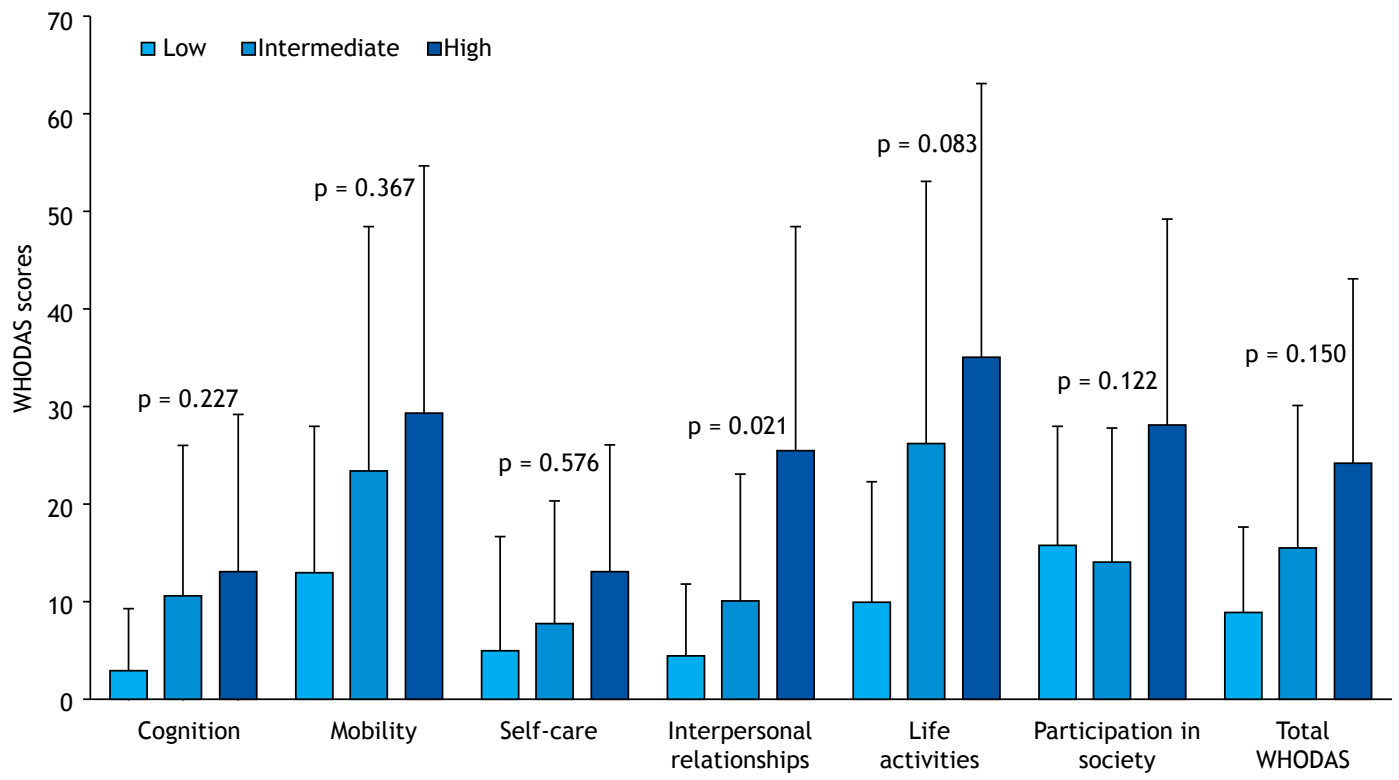

Figure 1. Mean World Health Organization Disability Assessment Schedule 2.0 (WHODAS 2.0) scores in the study population at baseline according to (A) gender and (B) pulmonary hypertension risk classification. Error bars represent standard deviations.

follow-up time of approximately 11 months, few patients $(13.0 \%)$ showed disease progression. There was a slight improvement in WHO functional class, with the proportion of patients in functional classes I/II increasing from 71.7 to $76.1 \%$. 6MWD also increased slightly from baseline to final visit (mean improvement of $5.6 \pm 85.8$ meters). Mean levels of NT-proBNP increased substantially from baseline to final visit, from a 2-fold elevation at baseline to a 3-fold elevation at final visit. The number of patients in intermediate and high risk slightly increased from 54.3 to $60.9 \%$ and from 19.5 to $23.9 \%$, respectively.

Table 5 explores the association between baseline WHODAS 2.0 scores and patient evolution in terms of 6MWD and NT-proBNP levels at final visit. In bivariate analysis, 6MWD at final visit was strongly associated with 
Table 2. Correlation results for the relationship between patient characteristics at baseline and World Health Organization Disability Assessment Schedule 2.0 (WHODAS 2.0) scores.

\begin{tabular}{|c|c|c|c|c|c|c|c|}
\hline & Cognition & Mobility & Self-care & $\begin{array}{l}\text { Interpersonal } \\
\text { relationship }\end{array}$ & $\begin{array}{c}\text { Life } \\
\text { activities }\end{array}$ & $\begin{array}{l}\text { Participation } \\
\text { in society }\end{array}$ & Total \\
\hline Age, years & 0.042 & $0.306^{*}$ & 0.182 & $0.371^{*}$ & $0.340^{*}$ & 0.148 & $0.405^{* *}$ \\
\hline Schooling, years & -0.217 & $-0.400^{* *}$ & $-0.308^{*}$ & $-0.458^{* *}$ & $-0.452^{* *}$ & $-0.411^{* *}$ & $-0.501^{* * *}$ \\
\hline Working status & 0.066 & 0.213 & 0.227 & 0.232 & 0.232 & 0.106 & $0.317^{*}$ \\
\hline PH aetiology & 0.191 & 0.175 & 0.105 & $0.328^{*}$ & $0.295^{*}$ & 0.209 & $0.343^{*}$ \\
\hline $\begin{array}{l}\text { Self-reported } \\
\text { dyspnoea }\end{array}$ & 0.207 & 0.146 & 0.175 & 0.341 & $0.337^{*}$ & 0.190 & 0.273 \\
\hline $\begin{array}{l}\text { Self-reported fatigue } \\
\text { No } \\
\text { Yes }\end{array}$ & $0.451^{* *}$ & $0.540^{* *}$ & $0.369^{*}$ & 0.222 & $0.512^{* * *}$ & $0.390^{* *}$ & $0.515^{* * *}$ \\
\hline $\begin{array}{l}\text { WHO Functional class } \\
\qquad \begin{array}{l}\text { I/II } \\
\text { III/IV }\end{array}\end{array}$ & $0.629^{* * *}$ & $0.591^{* * *}$ & $0.590^{* * *}$ & $0.598^{* * *}$ & $0.560^{* * *}$ & $0.596^{* * *}$ & $0.671^{* * *}$ \\
\hline $6 \mathrm{MWD}$, meters & -0.389 & $-0.417^{* *}$ & -0.229 & $-0.349^{*}$ & $-0.393^{* *}$ & -0.212 & $-0.419^{* *}$ \\
\hline Borg (dyspnoea) & 0.293 & $0.467^{* *}$ & 0.251 & $0.476^{* *}$ & $0.424^{* *}$ & $0.571^{* * *}$ & $0.561^{* * *}$ \\
\hline Borg (fatigue) & $0.583^{* * *}$ & $0.627^{* * *}$ & $0.420^{* *}$ & $0.598^{* * *}$ & $0.554^{* * *}$ & $0.699^{* * *}$ & $0.738^{* * *}$ \\
\hline Pulse pressure & $-0.401^{* *}$ & -0.207 & $-0.400^{* *}$ & -0.260 & -0.217 & $-0.298^{*}$ & -0.233 \\
\hline Sat_bas, mmHg & -0.074 & -0.044 & -0.175 & -0.206 & $-0.326^{*}$ & -0.035 & -0.338 \\
\hline Creatinine (mg/dL) & 0.200 & 0.052 & 0.029 & 0.210 & $0.340^{*}$ & 0.146 & 0.243 \\
\hline NT-proBNP, pg/mL & 0.231 & 0.111 & 0.193 & $0.405^{* *}$ & 0.148 & 0.192 & 0.272 \\
\hline $\mathrm{Cl}, \mathrm{L} / \mathrm{min} / \mathrm{m}^{2}$ & -0.198 & 0.068 & -0.044 & $-0.394^{*}$ & -0.257 & -0.074 & -0.167 \\
\hline PVR, Wood units & 0.091 & -0.140 & 0.025 & 0.159 & 0.169 & 0.134 & 0.025 \\
\hline Oxygen Therapy & 0.191 & $0.306^{*}$ & $0.290^{*}$ & $0.336^{*}$ & $0.295^{*}$ & 0.227 & $0.309^{*}$ \\
\hline $\begin{array}{l}\text { Risk classification }^{\mathrm{a}} \\
\text { Low } \\
\text { Intermediate } \\
\text { High }\end{array}$ & 0.220 & 0.211 & 0.154 & $0.399^{* *}$ & $0.327^{*}$ & 0.144 & 0.283 \\
\hline
\end{tabular}

PH: pulmonary hypertension; WHO: World Health Organization; 6MWD: 6-minute walk distance test; Sat bas: basal oxygen saturation; NT-proBNP: N-terminal pro b-type natriuretic peptide; CI: cardiac index; PVR: pulmonary vascular resistance. For the purpose of brevity, only variables with significant results are displayed in the table. The following variables were considered for statistical analysis, but did not reach statistical significance: gender, marital status, disease duration, comorbidities, number of comorbidities, body mass index (BMI), basal heart rate (HR_Bas), maximum heart rate (HR_Max), maximum - basal heart rate (DeltaHR), systolic blood pressure (SBP), diastolic blood pressure (DBP), minimum oxygen saturation (Sat_min), basal - minimum oxygen saturation (DeltaSat), right atrial pressure (RAP), mean pulmonary arterial pressure (mPAP), haemoglobin, haematocrit, oral anticoagulants, diuretics, PH specific therapy, number of PH specific drugs, PH specific oral route, $\mathrm{PH}$ specific parenteral route, other drugs, number of other drugs. Correlation coefficients calculated using Spearman's rank (quantitative vs. quantitative variables) or point-biserial (quantitative vs. categorical). ${ }^{a}$ Estimated risk of 1 -year mortality, according to the 2015 ESC/ERS guidelines risk assessment scale. $* p<0.05 ; * * p<0.01 ; * * * p<0.001$. Correlations with $\mathrm{p}<0.01$ are presented in bold.

all WHODAS 2.0 dimensions except cognition, whereas NT-proBNP levels only showed a weak association with the cognition, mobility, and life activities domains. In multivariate analysis, 6MWD at final visit was significantly associated with the interpersonal relationships domains, whereas NT-proBNP was significantly associated with the mobility and self-care domains.

The relationship between WHODAS 2.0 scores and WHO functional class and occurrence of disease progression was assessed through binary logistic regression, with no significant results for any of WHODAS domains. Nonetheless, total WHODAS 2.0 score at baseline was significantly associated with WHO functional class at final visit (odds ratio-OR: 1.124 [1.051-1.203; $\mathrm{p}<0.001]$ ).

Lastly, the predictive power of WHODAS 2.0 scores in terms of risk classification at last visit was assessed through ordinal regression. This analysis revealed a statistically significantly association only for the mobility domain (estimate: 3.919 [0.746-7.092]; p $<0.05)$. The correct overall classification percentage between the observed and the predicted categories was $66.7 \%$, with the following distribution of risk: low $(14.2 \%)$, intermediate $(89.3 \%)$, and high (54.5\%).

\section{DISCUSSION}

This study provides, to our knowledge, the first characterisation of disability in patients with $\mathrm{PH}$ based on the WHODAS 2.0 standardised assessment instrument. Using this type of tool to access disability across varied populations-both in terms of location and diseases states-, it can provide valuable insights in establishing better clinical care and improving overall public health. WHODAS 2.0 is particularly useful for these types of 
Table 3. Multivariate linear regression ( $\beta$ coefficients and the correspondent $95 \% \mathrm{CI}$ ) for the relationship between patient characteristics at baseline and World Health Organization Disability Assessment Schedule 2.0 (WHODAS 2.0) scores.

\begin{tabular}{|c|c|c|c|c|c|c|c|}
\hline & Cognition & Mobility & Self-care & $\begin{array}{l}\text { Interpersonal } \\
\text { relationship }\end{array}$ & $\begin{array}{l}\text { Life } \\
\text { activities }\end{array}$ & $\begin{array}{l}\text { Participation } \\
\text { in society }\end{array}$ & Total \\
\hline Schooling, years & & & & & & $\begin{array}{c}-5.4 \\
{[-10.4 ;-0.3]}\end{array}$ & \\
\hline Self-reported fatigue & & - & & & - & & \\
\hline $\begin{array}{l}\text { No } \\
\text { Yes }\end{array}$ & & $\begin{array}{c}18.7 \\
{[8.3 ; 29.0]}\end{array}$ & & & $\begin{array}{c}36.3 \\
{[20.8 ; 51.8]}\end{array}$ & & $\begin{array}{c}9.2 \\
{[2.7 ; 15.8]}\end{array}$ \\
\hline WHO Functional class & - & - & - & & & & - \\
\hline $\begin{array}{l}\text { I/II } \\
\text { III/IV }\end{array}$ & $\begin{array}{c}19.7 \\
{[12.8 ; 26.7]}\end{array}$ & $\begin{array}{c}24.5 \\
{[13.2 ; 35.9]}\end{array}$ & $\begin{array}{c}15.3 \\
{[8.2 ; 22.3]}\end{array}$ & & & & $\begin{array}{c}18.1 \\
{[10.9 ; 25.2]}\end{array}$ \\
\hline Borg (fatigue) & & & & $\begin{array}{c}2.7 \\
{[1.6 ; 3.8]}\end{array}$ & & $\begin{array}{c}2.58 \\
{[1.23 ; 3.94]}\end{array}$ & \\
\hline Pulse pressure & $\begin{array}{c}-0.23 \\
{[-0.45 ;-0.01]}\end{array}$ & & & & & $\begin{array}{c}-0.37 \\
{[-0.63 ;-0.11]}\end{array}$ & \\
\hline Creatinine $(\mathrm{mg} / \mathrm{dL})$ & & & & & $\begin{array}{c}34.3 \\
{[12.5 ; 56.1]}\end{array}$ & & \\
\hline NT-proBNP, pg/mL & & & & $\begin{array}{c}0.01 \\
{[0.00 ; 0.01]}\end{array}$ & & & \\
\hline Constant & $\begin{array}{c}15.1 \\
{[3.5 ; 26.8]}\end{array}$ & $\begin{array}{c}7.2 \\
{[1.3 ; 13.1]}\end{array}$ & & & & $\begin{array}{c}34.2 \\
{[16.7 ; 51.8]}\end{array}$ & \\
\hline $\mathrm{R}^{2}$ Ajustated & 0.477 & 0.534 & 0.301 & 0.445 & 0.483 & 0.454 & 0.539 \\
\hline
\end{tabular}

CI: cardiac index; WHO: World Health Organisation; NT-proBNP: N-terminal pro b-type natriuretic peptide. For the purpose of brevity, only variables with significant results are displayed in the table. The following variables were considered for statistical analysis, but did not reach statistical significance: age, gender, marital status, working status, pulmonary hypertension (PH) aetiology, disease duration, self-reported dyspnoea, comorbidities, number of comorbidities, body mass index (BMI), 6-minute walk distance test (6MWD), Borg (dyspnoea), basal heart rate (HR_Bas), maximum heart rate (HR_Max), maximum - Basal heart rate (DeltaHR), systolic blood pressure (SBP), diastolic blood pressure (DBP), minimum oxygen saturation (Sat_min), basal oxygen saturation (Sat_bas), basal - minimum oxygen saturation (DeltaSat), right atrial pressure (RAP), mean pulmonary arterial pressure (mPAP), haemoglobin, haematocrit, CI, pulmonary vascular resistance (PVR), oxygen therapy, oral anticoagulants, duretics, $\mathrm{PH}$ specific therapy, number of PH specific drugs, $\mathrm{PH}$ specific oral route, $\mathrm{PH}$ specific parenteral route, other drugs, number of other drugs, ESC/ERC risk classification. $\mathrm{R}^{2}$ Adjusted represents the proportion of variability explained by the proposed model. Relationships with $\mathrm{p}<0.01$ are presented in bold.

assessments, because it is based on the biopsychological model of functioning and disability defined by the ICF, which takes into account the degree on disability actually perceived by the individuals and, therefore, constitutes a better basis for targeted therapeutic interventions and public health policies. Also, being a standardized tool, it allows comparative studies with other health conditions and in different contexts.

The population of $\mathrm{PH}$ patients in this study showed low to intermediate $\mathrm{PH}$ disease severity, despite a disease duration of approximately seven years. Low to intermediate disease severity is reflected in the degree of disability observed in the study population according to WHODAS 2.0 scores, which showed mostly mild disability for individual WHODAS 2.0 domains and WHODAS 2.0 total score $(15.3 \pm 15.2)$. The domains of mobility and life activities were the ones in which patients showed more disability, which could be expected given the impairments in exercise capacity that characterise $\mathrm{PH} .{ }^{(1)}$

The degree of disability observed in this population is markedly lower than previous reports in populations with cardiorespiratory conditions with somewhat comparable disease manifestations. ${ }^{(19)}$ Racca et al. assessed disability in a population of ischaemic heart disease patients, reaching a mean total WHODAS
2.0 score of approximately 24 points (with a score of approximately 50 for the life activities domain). (21) Pedro-Cuesta et al. assessed disability in a population of patients with chronic obstructive pulmonary disease, chronic heart failure, or stroke and found total WHODAS 2.0 scores of 26,38 , and 28 , respectively. ${ }^{(22)}$ In a large population of patients with chronic diseases-including patients with ischemic heart disease-, Garin et al. reported a total WHODAS 2.0 score of $24.8 \pm 19.3$, with scores in the life activities domain of $37 . .^{(23)}$ The authors provided, however, estimates of disability according to disease severity, and our results are, actually, comparable to those of patients with ischaemic heart disease of mild to moderate severity. ${ }^{(23)}$

These findings support the assertion that the low degree of disability observed in our study population can be explained by the disease severity endured by the patients. We hypothesise that the relatively mild disability in the context of this highly debilitating and progressive disease is associated with the type of clinical management provided to these patients, which are followed in a highly-specialised PH treatment unit, without difficulties in accessing approved $\mathrm{PH}$-specific drugs. Importantly, $84.8 \%$ of patients were under treatment with $\mathrm{PH}$-specific drugs, 59\% in combination therapy, which is expected to result in better disease 
control and substantially fewer disease manifestations, thus vastly improving overall patient functioning.

The main baseline variables associated with disability measured through WHODAS 2.0 in this study cohort were WHO functional class, fatigue (and Borg fatigue index), dyspnoea (and Borg dyspnoea index), 6MWD, and NT-proBNP. These results are largely in agreement with previous studies assessing general health status and health-related quality of life in $\mathrm{PH}$ populations. ${ }^{(5)}$ Several studies identified WHO functional class, ${ }^{(24-28)}$ fatigue, ${ }^{(24,25)}$ and dyspnoea ${ }^{(24,25)}$ to be highly associated

Table 4. Clinical characteristics of the study population at final visit (end of study).

\begin{tabular}{lc}
\multicolumn{1}{c}{ Characteristics } & $\begin{array}{c}\text { PH patients } \\
\text { (n }=46)\end{array}$ \\
Follow-up time, days & $337.4 \pm 140.1$ \\
Disease progression, $\mathrm{n} \mathrm{( \% )}$ & \\
$\quad$ Yes & $6(13.0)$ \\
$\quad$ No & $40(87.0)$ \\
WHO Functional class, n (\%) & \\
I/II & $35(76.1)$ \\
III/IV & $11(23.9)$ \\
6MWD, meters & $412.7 \pm 134.8$ \\
NT-proBNP, pg/mL & $585.6 \pm 1046.3$ \\
Risk classification, $\mathrm{n} \mathrm{( \% )}$ & \\
$\quad$ Low & $7(15.2)$ \\
Intermediate & $28(60.9)$ \\
High & $11(23.9)$ \\
\hline
\end{tabular}

PH: Pulmonary hypertension; WHO: World Health Organisation; 6MWD: 6-minute walking distance; NTproBNP: N-terminal pro b-type natriuretic peptide. Data displayed as mean \pm standard deviation (SD), except when otherwise indicated. with overall health status and health-related quality of life. Additionally, there was an important negative correlation between education and scores for the domain of participation in society; this effect is, however, likely associated with the social involvement of participants in their communities, irrespective of $\mathrm{PH}$.

Several variables that are usually important for the clinical management of $\mathrm{PH}$ patients showed only weak or even no correlation with disability scores. Age and $\mathrm{PH}$ aetiology did not reach statistical significance in the multivariate regression model, which indicates that other variables are more important in a multivariate context. Similarly, PH risk classification showed sporadic significant correlations with disability scores in bivariate analysis, but it was not considered a significant factor in the multivariate model. On the other hand, disease duration, $\mathrm{PH}$-specific treatment, and the presence of comorbidities did not even show significant correlations in bivariate analysis. These results could potentially be explained by reduced variability in this relatively small population.

When using WHODAS 2.0 scores at baseline to predict evolution of $\mathrm{PH}$ markers over the 11-month period of the study, disability scores were only robustly predictive of 6MWD and WHO functional class evolution. There were a strong negative correlation between the mobility domain and 6MWD at final visit and a strong positive correlation between WHODAS 2.0 total score and WHO functional class at last visit, as would also be expected in both cases.

Some limitations of this study should be considered. The study had a moderate sample size $(\mathrm{N}=46)$ even in the context of $\mathrm{PH}$, which is an infrequent

Table 5. Correlation and multivariate linear regression for the relationship between World Health Organization Disability Assessment Schedule 2.0 (WHODAS 2.0) scores and patient evolution measured at final visit (end of study).

\begin{tabular}{|c|c|c|c|c|}
\hline \multirow[b]{2}{*}{$\begin{array}{l}\text { WHODAS } 2.0 \\
\text { Dimensions }\end{array}$} & \multicolumn{2}{|c|}{ 6MWD } & \multicolumn{2}{|c|}{ NT-proBNP } \\
\hline & $\begin{array}{l}\text { Correlation } \\
\text { coefficient }\end{array}$ & $\begin{array}{c}\text { Linear regression B } \\
{[95 \% \mathrm{Cl}]}\end{array}$ & $\begin{array}{l}\text { Correlation } \\
\text { coefficient }\end{array}$ & $\begin{array}{c}\text { Linear regression } B \\
{[95 \% \mathrm{Cl}]}\end{array}$ \\
\hline Cognition & -0.299 & $\begin{array}{c}1.82 \\
{[-1.05 ; 4.70]}\end{array}$ & $0.351^{*}$ & $\begin{array}{c}20.80 \\
{[3.51 ; 45.11]}\end{array}$ \\
\hline Mobility & $-0.616^{* * *}$ & $\begin{array}{c}-3.48^{* *} \\
{[-5.95 ;-1.01]}\end{array}$ & $0.361^{*}$ & $\begin{array}{c}36.88^{* * *} \\
{[16.42 ; 57.34]}\end{array}$ \\
\hline Self-care & $-0.527^{* * *}$ & $\begin{array}{c}0.420 \\
{[-3.11 ; 3.95]}\end{array}$ & -0.075 & $\begin{array}{c}-65.75^{* * *} \\
{[-93.22 ;-38.29]}\end{array}$ \\
\hline $\begin{array}{l}\text { Interpersonal } \\
\text { relationship }\end{array}$ & $-0.599^{* * *}$ & $\begin{array}{c}-5.19^{* * *} \\
{[-7.97 ;-2.40]}\end{array}$ & 0.207 & $\begin{array}{c}14.32 \\
{[-8.46 ; 37.11]}\end{array}$ \\
\hline Life activities & $-0.508^{* * *}$ & $\begin{array}{c}-0.909 \\
{[-2.86 ; 1.04]}\end{array}$ & $0.300^{*}$ & $\begin{array}{c}-4.79 \\
{[-21.28 ; 11.70]}\end{array}$ \\
\hline $\begin{array}{l}\text { Participation in } \\
\text { society }\end{array}$ & $-0.450^{* * *}$ & $\begin{array}{c}3.13 \\
{[-0.42 ; 6.67]}\end{array}$ & 0.267 & $\begin{array}{c}2.35 \\
{[-27.69 ; 32.39]}\end{array}$ \\
\hline Constant & NA & $\begin{array}{c}494.5^{* * *} \\
{[449.7 ; 539.2]}\end{array}$ & NA & $\begin{array}{c}38.0 \\
{[-338.3 ; 414.3]}\end{array}$ \\
\hline $\mathrm{R}^{2}$ Ajustated & NA & 0.498 & NA & 0.401 \\
\hline
\end{tabular}

6MWD: 6-minute walk distance test; NT-proBNP: N-terminal pro b-type natriuretic peptide: NA: not applicable; $95 \%$ CI: confidence interval of $95 \%$. For the purpose of brevity, only variables with significant results are displayed in the table. The following variables were considered for statistical analysis, but did not reach statistical significance: Delta_6MWD; Delta NT-proBNP. Correlation coefficients calculated using Spearman's rank (quantitative vs. quantitative variables) or point-biserial (quantitative vs. categorical). $\mathrm{R}^{2}$ Adjusted represents the proportion of variability explained by the proposed model. $* p<0.05 ; * * p<0.01 ; * * * p<0.001$. 
condition. The sample was compounded with only a small number of patients with severe forms of $\mathrm{PH}$ $(19.5 \%)$ that are expected to show substantially higher degrees of disability, which limits comparisons with previous reports from populations with higher levels of disability. Further studies should focus on assessing more heterogeneous $\mathrm{PH}$ populations in terms of disease severity. Additionally, the study had a relatively short mean follow-up time, which could hinder the assessment of the predictive value of baseline WHODAS 2.0 scores, since few events of interest occurred throughout the period of the study.

In conclusion, this population of Portuguese $\mathrm{PH}$ patients shows mild disability as assessed through WHODAS 2.0, which can be associated with low to intermediate disease severity. Higher degree of disability is found in the domains of mobility and life activities. The main clinical correlates of disability in this population are WHO functional class, fatigue, and dyspnoea. WHODAS 2.0 scores at baseline predict 6MWD and WHO functional class over an 11-month follow-up period.

This study was the first one to assess disability in PH using WHODAS 2.0. Further studies should apply this scale to larger $\mathrm{PH}$ populations with suitable representations of more severe forms of $\mathrm{PH}$.

\section{ACKNOWLEDGMENTS}

Pedro Sa-Couto's work was supported in part by the Fundação para a Ciência e a Tecnologia (FCT), through Center for Research and Development in Mathematics and Applications (CIDMA), within project ID/MAT/04106/2013. The authors thank Tiago Campos, MSc (ARC Publishing), for providing medical writing and editorial assistance; these services were supported by an unrestricted grant from Actelion Pharmaceuticals, from Portugal.

\section{REFERENCES}

1. Galiè N, Humbert M, Vachiery J-L, Gibbs S, Lang I, Torbicki A, et al. 2015 ESC/ERS Guidelines for the diagnosis and treatment of pulmonary hypertension: The Joint Task Force for the Diagnosis and Treatment of Pulmonary Hypertension of the European Society of Cardiology (ESC) and the European Respiratory Society (ERS)Endorse. Eur Heart J. 2016;37(1):67-119. https://doi. org/10.1093/eurheartj/ehv317

2. Anderson RJ, Malhotra A, Kim NH. Pulmonary hypertension: evolution of pulmonary arterial hypertension and chronic thromboembolic pulmonary hypertension. J Thorac Dis. 2016;8(Suppl. 7):S562-5. https://dx.doi. org/10.21037\%2Fjtd.2016.07.33

3. Burger CD, D'Albini L, Raspa S, Pruett JA. The evolution of prostacyclins in pulmonary arterial hypertension: from classical treatment to modern management. Am J Manag Care. 2016;22(1 Suppl.):S3-15.

4. Delcroix M, Howard L. Pulmonary arterial hypertension: the burden of disease and impact on quality of life. Eur Respir Rev. 2015;24(138):621-9. https://doi.org/10.1183/16000617.0063-2015

5. Gu S, Hu H, Dong H. Systematic Review of Health-Related Quality of Life in Patients with Pulmonary Arterial Hypertension. Pharmacoeconomics. 2016;34(8):751-70. https://doi.org/10.1007/ s40273-016-0395-y

6. Oudiz RJ, Barst RJ. Statement on Disability: Pulmonary Hypertension. Pulmonary Hypertension Association; 2010.

7. Ware JE Jr., Sherbourne CD. The MOS 36-item short-form health survey (SF-36). I. Conceptual framework and item selection. Med Care. 1992;30(6):473-83.

8. Hunt SM, McKenna SP, McEwen J, Williams J, Papp E. The Nottingham Health Profile: subjective health status and medical consultations. Soc Sci Med A. 1981;15(3 Pt 1):221-9.

9. EuroQol Group. EuroQol--a new facility for the measurement of health-related quality of life. Health Policy. 1990;16(3):199-208.

10. McKenna SP, Doughty N, Meads DM, Doward LC, Pepke-Zaba J. The Cambridge Pulmonary Hypertension Outcome Review (CAMPHOR): a measure of health-related quality of life and quality of life for patients with pulmonary hypertension. Qual Life Res. 2006;15(1):103-15. https://doi.org/10.1007/s11136-005-3513-4

11. Rector T, Kubo S, Cohn J. Patients' self-assessment of their congestive heart failure. Part 2: Content, reliability and validity of a new measure, the Minnesota Living with Heart Failure Questionnaire. Hear Fail. 1987;3:198-209.

12. Bonner N, Abetz L, Meunier J, Sikirica M, Mathai SC. Development and validation of the living with pulmonary hypertension questionnaire in pulmonary arterial hypertension patients. Health Qual Life Outcomes. 2013:11:161. https://doi.org/10.1186/14777525-11-161

13. Guyatt GH, Nogradi S, Halcrow S, Singer J, Sullivan MJ, Fallen EL.
Development and testing of a new measure of health status for clinical trials in heart failure. J Gen Intern Med. 1989;4(2):101-7.

14. Yorke J, Corris P, Gaine S, Gibbs JSR, Kiely DG, Harries C, et al. emPHasis-10: development of a health-related quality of life measure in pulmonary hypertension. Eur Respir J 2014;43(4):1106-13. https://doi.org/10.1183/09031936.00127113

15. McCollister D, Shaffer S, Badesch DB, Filusch A, Hunsche E, Schüler R, et al. Development of the Pulmonary Arterial Hypertension-Symptoms and Impact (PAH-SYMPACT®) questionnaire: a new patient-reported outcome instrument for PAH. Respir Res. 2016;17(1):72. https://doi.org/10.1186/s12931 016-0388-6

16. Fernandes CJCS, Martins BCS, Jardim CVP, Ciconelli RM, Morinaga LK, Breda AP, et al. Quality of life as a prognostic marker in pulmonary arterial hypertension. Health Qual Life Outcomes. 2014;12:130. https://doi.org/10.1186/s12955-014-0130-3

17. World Health Organization. International Classification of Functioning, Disability and Health (ICF). Geneva: World Health Organization; 2001.

18. Üstün T, Kostanjsek N, Chatterji S, Rehm J. Measuring Health and Disability: Manual for WHO Disability Assessment Schedule WHODAS 2.0. Geneva: World Health Organization; 2010

19. Federici S, Bracalenti M, Meloni F, Luciano JV. World Health Organization disability assessment schedule 2.0: An international systematic review. Disabil Rehabil. 2017;39(23):2347-80. https:// doi.org/10.1080/09638288.2016.1223177

20. Ribeiro S. Adaptação e validação do WHODAS 2.0 para a população portuguesa [dissertation]. Aveiro: Escola Superior de Saúde da Universidade de Aveiro; 2011.

21. Racca V, Spezzaferri R, Modica M, Mazzini P, Jonsdottir J, De Maria $R$, et al. Functioning and disability in ischaemic heart disease. Disabil Rehabil. 2010;32(Suppl. 1):S42-9. https://doi.org/1 0.3109/09638288.2010.511691

22. Pedro-Cuesta J, Alberquilla Á, Virués-Ortega J, Carmona M, Alcalde-Cabero E, Bosca G, et al. ICF disability measured by WHO-DAS II in three community diagnostic groups in Madrid Spain. Gac Sanit. 2011;25(Suppl. 2):21-8. https://doi.org/10.1016/j. gaceta.2011.08.005

23. Garin O, Ayuso-Mateos JL, Almansa J, Nieto M, Chatterji S, Vilagut $G$, et al. Validation of the "World Health Organization Disability Assessment Schedule, WHODAS-2" in patients with chronic diseases. Health Qual Life Outcomes. 2010;8:51. https:// doi.org/10.1186/1477-7525-8-51

24. Zlupko M, Harhay MO, Gallop R, Shin J, Archer-Chicko C, Pate $R$, et al. Evaluation of disease-specific health-related quality of life in patients with pulmonary arterial hypertension. Respir Med. 2008;102(10):1431-8. https://doi.org/10.1016/j.rmed.2008.04.016

25. Taichman DB, Shin J, Hud L, Archer-Chicko C, Kaplan S, Sager JS, 
Disability and its clinical correlates in pulmonary hypertension measured through the World Health

Organization Disability Assessment Schedule 2.0: a prospective, observational study

et al. Health-related quality of life in patients with pulmonary arterial hypertension. Respir Res. 2005;6:92. https://doi.org/10.1186/14659921-6-92

26. Roman A, Barbera JA, Castillo MJ, Muñoz R, Escribano $P$. Health-related quality of life in a national cohort of patients with pulmonary arterial hypertension or chronic thromboembolic pulmonary hypertension. Arch Bronconeumol. 2013:49(5):181-8. https://doi.org/10.1016/j.arbres.2012.12.007
27. Halank $M$, Einsle $F$, Lehman $S$, Bremer $H$, Ewert $R$, Wilkens $\mathrm{H}$, et al. Exercise capacity affects quality of life in patients with pulmonary hypertension. Lung. 2013;191(4):337-43. https://doi. org/10.1007/s00408-013-9472-6

28. Matura LA, McDonough A, Carroll DL. Predictors of HealthRelated Quality of Life in Patients With Idiopathic Pulmonary Arterial Hypertension. J Hosp Palliat Nurs. 2012;14(4):283-92. https://doi.org/10.1097/NJH.0b013e3182496c04 